\title{
Emission of Isothiazolinones from Water-Based Paints
}

\author{
Michael D. Lundov, ${ }^{* \dagger}$ Barbara Kolarik, ${ }^{\ddagger}$ Rossana Bossi, ${ }^{\S}$ Lars Gunnarsen, ${ }^{\ddagger}$ and Jeanne D. Johansen ${ }^{\dagger}$ \\ ${ }^{\dagger}$ National Allergy Research Centre, Department of Dermato-Allergology, Gentofte University Hospital, Ledreborg Alle 40, 1., \\ DK-2820 Gentofte, Denmark \\ ${ }^{\ddagger}$ Department of Construction and Health, Danish Building Research Institute (SBI), Aalborg University, A.C. Meyers Vænge 15, \\ DK-2450 Copenhagen SV, Denmark \\ ${ }^{\S}$ Department of Environmental Science, Aarhus University, Frederiksborgvej 399, DK-4000 Roskilde, Denmark
}

ABSTRACT: The isothiazolinone preservatives methylisothiazolinone (MI), methylchloroisothiazolinone (MCI), and benzisothiazolinone (BIT) are used in a wide variety of products including paint and cosmetics, and they are known to cause allergic contact dermatitis. Among painters they are one of the most common causes of contact dermatitis. Furthermore, they are all volatile, and severe reactions caused by emissions of especially MI from paint have been reported recently. In

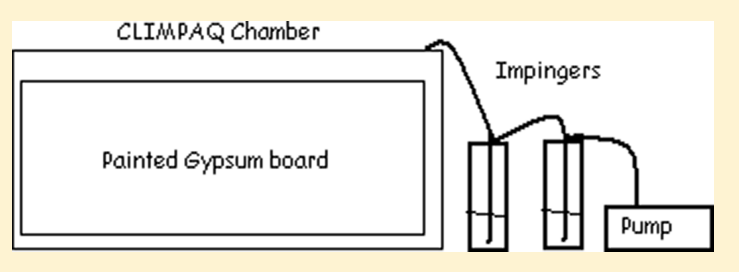
this study the concentrations of MI, BIT, and MCI in water-based paint were analyzed by LC-MS-MS, and the emissions from the paints were measured in climate chambers and in an apartment. Nineteen paints were analyzed for the content of MI, MCI, and BIT. All 19 paints contained MI, 16 contained BIT, and 4 contained MCI. In the chamber experiment emission of MI peaked within hours of application but then continued at a slow rate for more than 42 days. MCI was emitted more slowly and peaked after several days. BIT emissions were all around the limit of detection. In the apartment we were able to detect emission of MI several days after application. Long lasting evaporation and thus chronic exposure give credibility to the clinical observations that MI can be an important cause of airborne contact dermatitis among painters and consumers.

\section{INTRODUCTION}

The isothiazolinone preservatives (methylchloroisothiazolinone MCI, benzisothiazolinone BIT, and methylisothiazolinone MI) are widely used in many different products and industrial settings, like cosmetics, cleaning agents, paints, varnishes, and cooling agents. All the mentioned isothiazolinones are known to cause allergic contact dermatitis. The isothiazolinone combination $\mathrm{MCI} / \mathrm{MI}(3: 1)$ has been used in consumer and industrial products since the 1980s, and BIT has been used since the 1970s. The first case of allergic contact dermatitis due to isothiazolinone preservatives was published in 1976, ${ }^{1}$ and it was caused by BIT, which today rarely causes contact dermatitis. $^{2}$ It was quickly discovered that both MCI and MI were potent sensitizers, and the use of $\mathrm{MCI} / \mathrm{MI}$ was restricted. This caused the overall prevalence of $\mathrm{MCI} / \mathrm{MI}$ contact dermatitis to stabilize just above $2 \%$ in patch tested patients. ${ }^{3,4}$ MI alone has been used in industrial products since around year 2000, and in 2005 its use was permitted in cosmetic products at a maximum concentration of $0.01 \%(100 \mathrm{ppm})$. Since 2009 the prevalence of MI contact dermatitis has increased with an alarming pace. ${ }^{2,5,6}$ Among painters the isothiazolinones MCI/ MI, MI alone, octylisothiazolinone, and BIT are some of the most common reasons for occupational contact dermatitis. ${ }^{7}$ The majority of patients allergic to one or more of the isothiazolinones have classical symptoms of allergic contact dermatitis (eczema) on the skin site of direct exposures. However, the isothiazolinones are all volatile, and it has been shown several times that emission of isothiazolinones especially from paint has led to severe systemic allergic contact dermatitis reactions, both in patients directly exposed while painting but also in small children and adults who have not painted themselves but for instance moved into a newly painted house or apartment. ${ }^{8-13}$ Some of these patients have reacted to the isothiazolinone exposure with a severity that impairs them in going to work and being part of normal society. ${ }^{14}$ The clinical picture of airborne contact dermatitis is eczema at skin areas, often face and neck, not directly exposed to the allergen but exposed by deposition from the air, or systemic reactions where inhaled allergen leads to eczema in areas not exposed directly and in some cases asthmatic symptoms. The increasing incidence of allergic contact dermatitis among both painters and consumers and the severity of the reactions formed the background for our investigation. The aim of the study was to investigate the frequency and extent of use of the three isothiazolinones MCI, BIT, and MI in commercial paints as well as emission patterns of these compounds in laboratory and field settings.

\section{MATERIALS AND METHODS}

Analysis of Isothiazolinones in Paint. We purchased 18 wall paints in different constructions market and paint shops in the greater Copenhagen area, Denmark. Paint no. 19 was used in the fields experiment and was purchased by the owners of the apartment. The paints represented a wide range of the

Received: January 17, 2014

Revised: April 4, 2014

Accepted: May 28, 2014

Published: May 28, 2014 


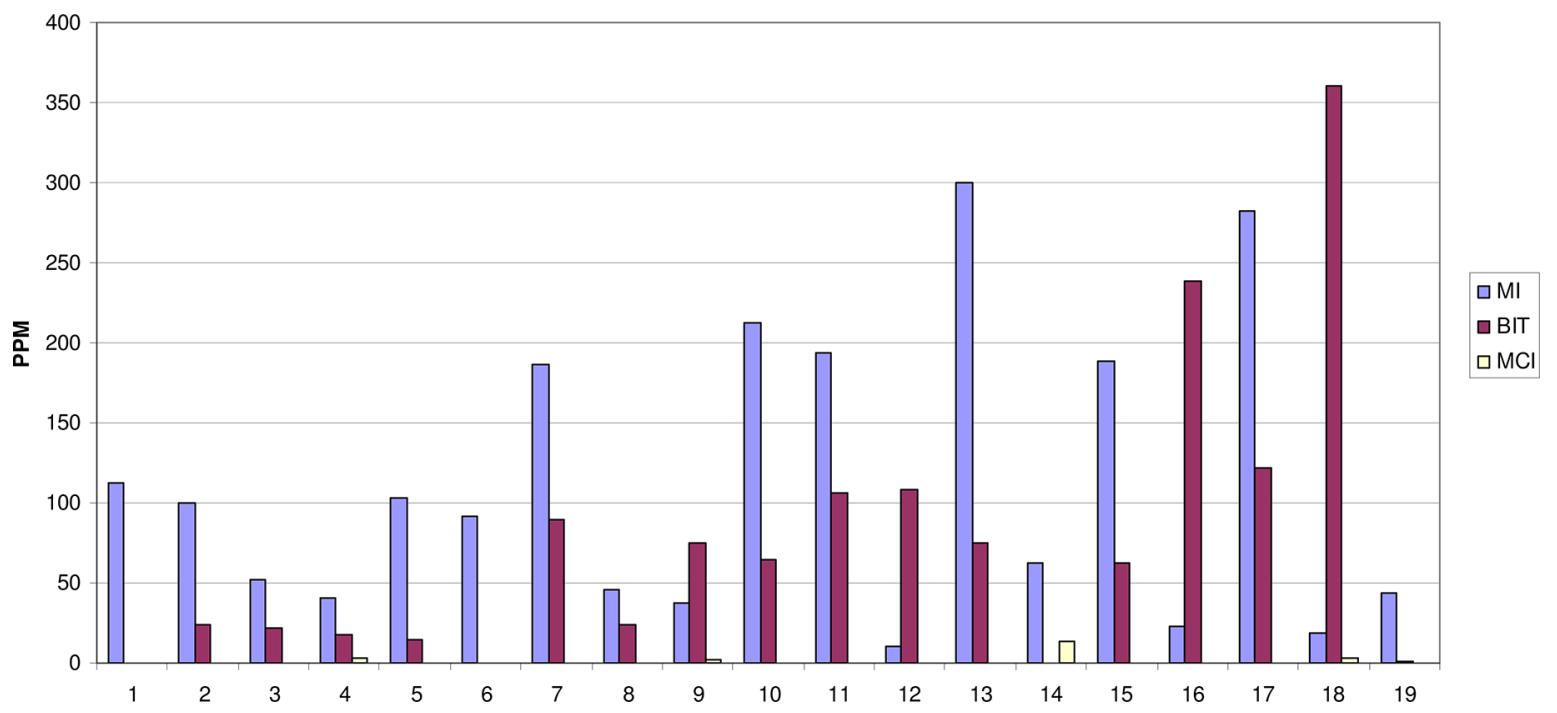

Figure 1. Concentration of methylisothiazolinone (MI), benzisothiazolinone (BIT), and methylchloroisothiazolinone (MCI) in the 19 different paints analyzed.

brands used in Denmark. The concentrations of MI, MCI, and BIT were measured in all samples. A $1 \mathrm{~g}( \pm 0.1 \mathrm{~g})$ sample from each paint was extracted in $25 \mathrm{~mL}$ methanol/0.4\% formic acid $(20: 80 \mathrm{v} / \mathrm{v})$ by means of ultrasound in $10 \mathrm{~min}$. The suspension was filtered through a Phenex-GF/CA (glassfiber/cellulose) filter and analyzed by high-performance liquid chromatography (HPLC) coupled to tandem mass spectrometry (MS-MS). The analytes were separated on a Kinetex C18 $(100 \times 2.1 \mathrm{~mm})$ HPLC column and ionized with electrospray ionization (ESI) operated in positive mode. The MS was operated in multiple reaction monitoring (MRM) with two mass transitions (parent ion/product ion) for each analyte $(m / z 116 / 101$ and $116 / 71$ for MI; $m / z 150 / 87$ and $150 / 135$ for MCI; $m / z 152 / 109$ and $152 / 134$ for $\mathrm{BI})$. Detection of the analytes was based on retention time and the most abundant mass transition corresponding to an authentic standard. Confirmation of analyte identity was based on the relative response of the secondary mass transition to the primary mass transition. Quantification of the analytes was done using response factors calculated from a four-point calibration curve.

The recovery of the extraction method for paint was calculated by spiking two different paints containing low amounts $(<0.5 \mu \mathrm{g} / \mathrm{mL})$ of the three analytes. The samples were spiked at two different concentrations, 4 and $10 \mu \mathrm{g} / \mathrm{mL}$. The average recoveries obtained for MI, CMI, and BI were 101, 128, and $107 \%$.

Recovery - Sampling with Impingers. The recovery and breakthrough of MI, MCI, and BI during sampling with impingers was tested by passing airflow $(9 \mathrm{~mL} / \mathrm{min})$ through two impingers connected in series containing $30 \mathrm{~mL}$ of pure water with $0.1 \%$ formic acid. The solution in the first impinger (A) was spiked with the 3 compounds to a concentration of 0.5 $\mu \mathrm{g} / \mathrm{mL}$ each, while the second impinger (B) only contained the blank solution. The concentrations of the 3 analytes were measured at $t=0$ and then at intervals of 1 day for 10 days by taking a $100 \mu \mathrm{L}$ aliquot from impinger $\mathrm{A}$ and $\mathrm{B}$, respectively. The compounds were not detected in impinger $B$, which means that no breakthrough of the compounds occurred at the tested flow rate and sampling time.

Precision of the Method (Extraction of Paint). The precision of the method was calculated as the relative standard deviation of replicate analysis of two paints $(n=10)$. The overall precision for MI and CMI was $1 \%$ and $2 \%$ for BI.

Laboratory Emission Tests. The experiment was conducted at Danish Building Research Institute (SBi), in small scale chambers for laboratory investigations of materials, pollution, and air quality (CLIMPAQ). ${ }^{15}$ The chambers are made of glass and have a volume of 511. Two gypsum boards painted twice on both sides were inserted into each chamber. The amount of paint applied was $17 \mathrm{~mL}$ per side, per layer, according to the manufacturer's recommendations. The paint was allowed to dry for $30 \mathrm{~min}$ before the second coating and again $30 \mathrm{~min}$ before the boards were put in the emission chamber. In one chamber paint no. 12 (Figure 1) was applied each time on both gypsum boards. In the second chamber the gypsum board was first coated with paint no. 17 and then with paint no. 18 (Figure 1). It was not meant to use to different paints; however, as we ran out of paint no. 17, we purchased a new one, which apparently had another gloss, and the later analysis of the isothiazolinone content showed differences in the type of isothiazolinones as well as in concentrations.

During the experiment, the chambers were ventilated with $0.17 \mathrm{~m}^{3} / \mathrm{h}$ of filtered air and conditioned to $23{ }^{\circ} \mathrm{C}$ and $50 \% \mathrm{RH}$. This flow rate results in the same area specific ventilation rate for painted surfaces as in a model room $(3.2 \times 2.2 \times 2.4 \mathrm{~m})$ ventilated with $0.5 \mathrm{~h}^{-1}$, where all walls and ceiling would be painted with the tested paint (DS/EN ISO 16000-9:2006).

Sampling of isothiazolinones was conducted by use of two serially connected impingers and a pump, which sampled the air directly from the emission chambers. Each impinger contained $30 \mathrm{~mL}$ of pure water with $0.1 \%$ formic acid. The first impinger collected the isothiazolinones from the air, and the second impinger in series served to control if there was any breakthrough of the analytes from the first impinger. Two FLEC air pumps were used for the two chamber settings, one, with a flow rate of $15 \mathrm{~mL} / \mathrm{min}$ and second, with a flow rate of 9 $\mathrm{mL} / \mathrm{min}$. Sampling was conducted 2, 4, 6, 8, 20, and $28 \mathrm{~h}$ after the painted gypsum boards were placed in the chamber and continued with 2-4 days interval until day 42. Each time 100 $\mu \mathrm{L}$ of the formic acid solution was collected into a HPLC vial with a $100 \mu \mathrm{L}$ insert and stored at $4{ }^{\circ} \mathrm{C}$ until analysis. 
Table 1. Concentrations of the Investigated Isothiazolinones Measured in a Laboratory Investigation (in $\mathrm{ng} / \mathrm{mL}$ ) and the Amount of Isothiazolinones Emitted over the Time of the Experiment (in $\mathrm{ng})^{a}$

\begin{tabular}{|c|c|c|c|c|c|c|c|c|c|c|}
\hline \multirow[b]{3}{*}{ time, day } & \multicolumn{4}{|c|}{ paint no. 12} & \multicolumn{6}{|c|}{ paint nos. 17 and 18} \\
\hline & \multicolumn{3}{|c|}{ concn, $\mathrm{ng} / \mathrm{mL}$} & \multirow{2}{*}{$\frac{\text { amount, ng }}{\mathrm{MI}}$} & \multicolumn{3}{|c|}{ concn, $\mathrm{ng} / \mathrm{mL}$} & \multicolumn{3}{|c|}{ amount, ng } \\
\hline & MI & MCI & BIT & & MI & MCI & BIT & MI & MCI & BIT \\
\hline 0.08 & $<\mathrm{LOD}$ & $<$ LOD & $<\mathrm{LOD}$ & & $<\mathrm{LOD}$ & $<\mathrm{LOD}$ & $<\mathrm{LOD}$ & & & \\
\hline 0.17 & $<\mathrm{LOD}$ & $<\mathrm{LOD}$ & $<\mathrm{LOD}$ & & $<\mathrm{LOD}$ & $<\mathrm{LOD}$ & $<\mathrm{LOD}$ & & & \\
\hline 0.25 & $<\mathrm{LOD}$ & $<\mathrm{LOD}$ & $<\mathrm{LOD}$ & & 2.2 & 0.3 & $<$ LOD & 65 & 9 & \\
\hline 0.33 & $<\mathrm{LOD}$ & $<$ LOD & $<\mathrm{LOD}$ & & 3.0 & 0.5 & $<\mathrm{LOD}$ & 89 & 15 & \\
\hline 0.85 & $<\mathrm{LOD}$ & $<\mathrm{LOD}$ & $<\mathrm{LOD}$ & & 5.5 & 0.4 & $<\mathrm{LOD}$ & 163 & $b$ & \\
\hline 1.14 & $<\mathrm{LOD}$ & $<$ LOD & $<\mathrm{LOD}$ & & 7.8 & 1.3 & $<\mathrm{LOD}$ & 231 & 38 & \\
\hline 2.00 & 0.6 & $<$ LOD & $<\mathrm{LOD}$ & 18 & 8.3 & 2.4 & $<\mathrm{LOD}$ & 245 & 70 & \\
\hline 3.00 & 1.2 & $<\mathrm{LOD}$ & $<\mathrm{LOD}$ & 35 & 15.0 & 3.8 & $<\mathrm{LOD}$ & 439 & 111 & \\
\hline 3.99 & 1.3 & $<\mathrm{LOD}$ & $<\mathrm{LOD}$ & 38 & 17.0 & 3.4 & $<\mathrm{LOD}$ & 497 & $b$ & \\
\hline 7.00 & 1.6 & $<$ LOD & $<\mathrm{LOD}$ & 46 & 23.0 & 3.8 & $<\mathrm{LOD}$ & 666 & 111 & \\
\hline 9.00 & 2.1 & $<\mathrm{LOD}$ & $<\mathrm{LOD}$ & 60 & 28.0 & 4.4 & $<\mathrm{LOD}$ & 806 & 144 & \\
\hline 11.00 & 2.3 & $<\mathrm{LOD}$ & $<$ LOD & 66 & 30.0 & 5.0 & $<\mathrm{LOD}$ & 861 & 158 & \\
\hline 14.00 & 3.4 & $<\mathrm{LOD}$ & $<\mathrm{LOD}$ & 96 & 32.0 & 5.5 & $<\mathrm{LOD}$ & 916 & 161 & \\
\hline 16.99 & 3.5 & $<$ LOD & $<\mathrm{LOD}$ & 98 & 37.0 & 5.6 & $<\mathrm{LOD}$ & 1049 & 171 & \\
\hline 21.00 & 4.2 & 0.7 & $<\mathrm{LOD}$ & 117 & 40.0 & 6.0 & 0.9 & 1128 & 174 & 23.6 \\
\hline 24.01 & 4.9 & 0.6 & 0.4 & 135 & 43.0 & 6.1 & 0.9 & 1205 & 194 & 23.6 \\
\hline 28.00 & 3.9 & $<\mathrm{LOD}$ & 0.4 & $b$ & 49.0 & 6.9 & 0.8 & 1356 & 144 & $b$ \\
\hline 31.01 & 5.0 & $<$ LOD & 0.4 & 137 & 36.0 & 6.5 & 0.9 & $b$ & $b$ & 23.6 \\
\hline 35.00 & 5.1 & $<$ LOD & $<\mathrm{LOD}$ & 140 & 48.0 & 7.0 & 1.0 & $b$ & 196 & 26.0 \\
\hline 38.04 & 4.7 & $<\mathrm{LOD}$ & $<\mathrm{LOD}$ & $b$ & 53.0 & 7.4 & 1.3 & 1451 & 206 & 33.1 \\
\hline 42.10 & 4.6 & $<$ LOD & $<\mathrm{LOD}$ & $b$ & 58.0 & 8.3 & 1.4 & 1566 & 226 & 35.4 \\
\hline
\end{tabular}

${ }^{a}$ Abbreviations: MI: methylisothiazolinone. MCI: methylchloroisothiazolinone. BIT: benzisothiazolinone. LOD: limit of detection $=0.3 \mathrm{ng} / \mathrm{mL}$.

${ }^{b}$ Measurement giving negative change in concentration, not included in the analysis.

Field Emission Test. Field measurements were conducted in a $111 \mathrm{~m}^{3}$ apartment located in Copenhagen, Denmark. The field investigation was coupled into the study design at a later stage, which led to a lack of initial measurements. The apartment was namely painted 7 days before the measurements, and the used paint (no. 19 in Figure 1) was not tested under laboratory investigation. Two coatings were applied. The measurements took place in a $17.5 \mathrm{~m}^{2}$ living room $\left(46 \mathrm{~m}^{3}\right)$. The air change rate in the room was $0.8 \mathrm{~h}^{-1}$, and temperature and relative humidity were $22{ }^{\circ} \mathrm{C}$ and $30 \%\left( \pm 0.4{ }^{\circ} \mathrm{C}, 2.5 \%\right)$ during the measuring period. The measuring set up and sampling procedure were the same as for the laboratory tests. Samples were taken once a day, approximately at the same time, for a period of 10 days. Air change rate was measured by means of $\mathrm{CO}_{2}$ decay. The measurements were done with closed windows and doors. Approximately $5000 \mathrm{ppm}$ of $\mathrm{CO}_{2}$ was dosed to the room, and the measurements were done using carbon CARBOCAP $\mathrm{CO}_{2}$ monitors (GMW115, Vaisala, Finland; measurement uncertainty $\pm(2 \%$ of range $+2 \%$ of reading)) connected to a HOBO U12-013 data logger (Onset, USA). Temperature and relative humidity were measured by a HOBO U12-013 data logger. Chemical analysis of samples from both the laboratory emission tests and field experiment followed the same procedure as for determination of isothiazolinones in paints.

\section{RESULTS}

All 19 wall paints were preserved with MI, 16 with BIT, and 4 with MCI (Figure 1). The concentrations of MI ranged from 10 to $300 \mathrm{ppm}$. BIT was found in concentrations from 1.5 to 360 ppm, while measured MCI concentrations were 2, 3, 3, and $14 \mathrm{ppm}$.
Laboratory Emission Tests. Concentrations of MI, MCI, and BIT in the impingers $(\mathrm{ng} / \mathrm{mL})$ as well as the amount of isothiazolinones emitted over the time of the experiment are shown in Table 1. The corresponding air concentrations, in $\mu \mathrm{g} /$ $\mathrm{m}^{3}$, are shown in Figures 2-4. Only measurements with a

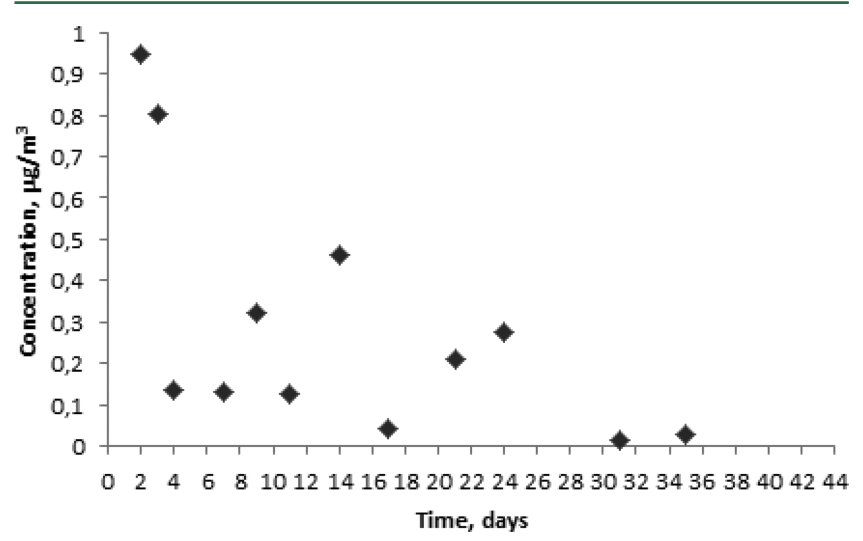

Figure 2. Emission of methylisothiazolinone from paint no. 12 (see Figure 1), measured in a laboratory investigation.

positive increment were included in the calculations of air concentrations of the measured compounds. As a result of our experimental conditions (sample size, area-specific ventilation rate), the results presented in Figures 2-4 can be directly translated to concentrations that would be expected in a model room (DS/EN ISO 16000-9:2006) painted with the tested paints.

In the chamber where paint no. 12 (Figure 1) having low MI concentration $(10 \mathrm{ppm})$ was applied, we obtained measurable air concentrations after 2 days, and already after 4 days the 
concentrations decreased significantly (Figure 2). For the remaining days of the experiment MI concentrations were fluctuating and approaching zero at a slow rate. This fluctuation pattern is even more pronounced in the measurements for the second chamber where a paint with a high MI content $(282$ ppm) was applied as the first layer and a paint with a low MI content was applied as the second layer (19 ppm) (Figure 1, paint nos. 17 and 18). MI could be detected already after $6 \mathrm{~h}$ and in concentrations more than 20 times higher compared to Figure 2. After 2 days the concentrations were fluctuating around $2 \mu \mathrm{g} / \mathrm{m}^{3}$, which is higher than the highest concentration measured in the other chamber (Figure 2 and 3), and

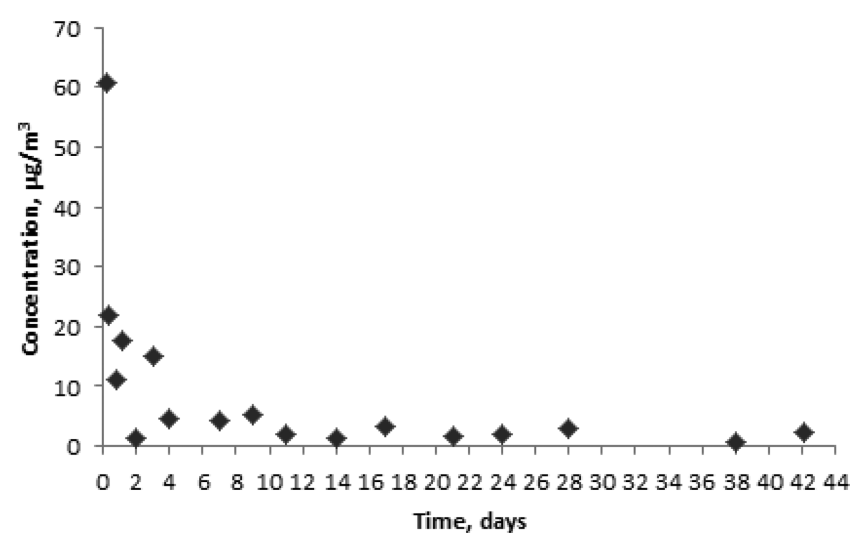

Figure 3. Emission of methylisothiazolinone from paint nos. 17 and 18 (see Figure 1) measured in a laboratory investigation.

approaching zero at a slow rate. The situation was similar for MCI (Figure 4), which was detected in paint no. 18 (Figure 1);

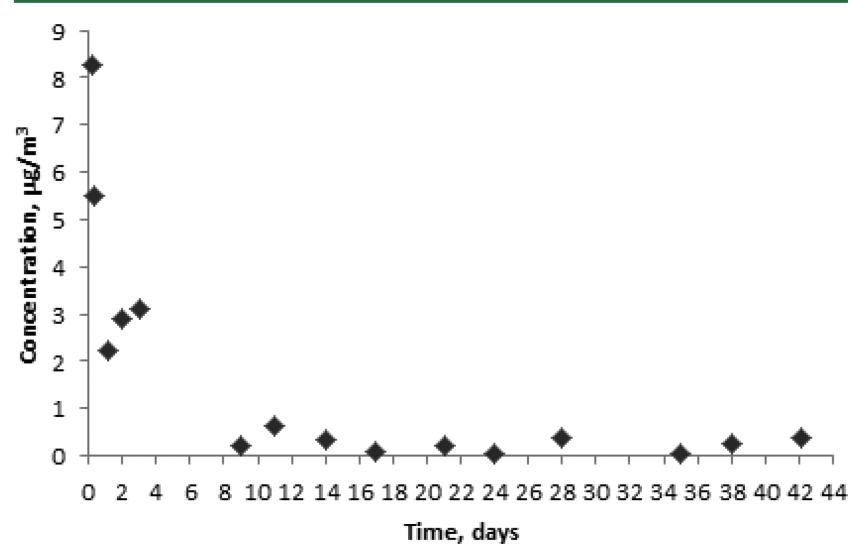

Figure 4. Emission of methylchloroisothiazolinone from paint nos. 17 and 18 (see Figure 1), measured in a laboratory investigation.

however, it took longer (around 10 days) for the concentration to decay. Concentration of BIT could be measured only in a few samples from both chambers, and the measured concentrations were close to detection limit (Table 1).

Field Test. The paint used in the apartment contained 44 ppm MI and 1.5 ppm BIT, while MCI was not detected (Figure 1, paint no. 19). Concentrations measured in the apartment are shown in Figure 5. The measurements were set up 1 week after painting, thus the concentration peak and initial decay cannot be observed from the collected data. Except for the first rather high value, the concentrations tend to fluctuate around $3 \mu \mathrm{g} /$ $\mathrm{m}^{3}$.

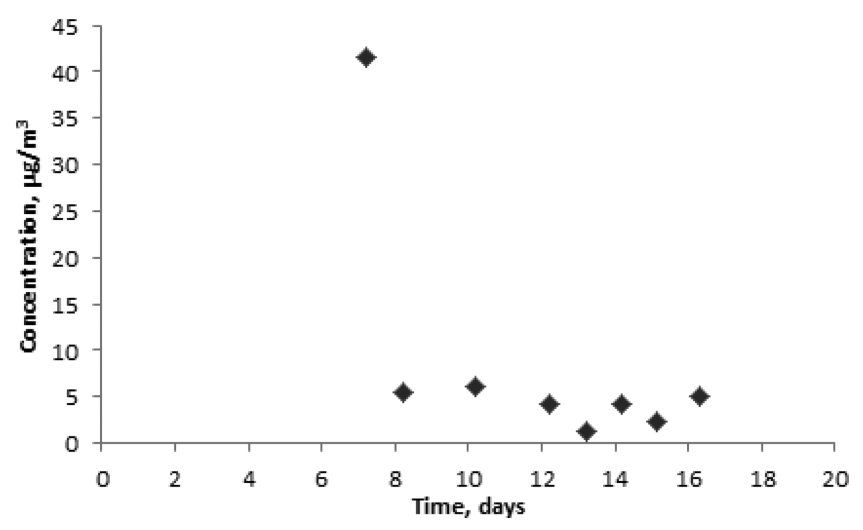

Figure 5. Emission of methylisothiazolinone from paint no. 19 (see Figure 1) measured in a field investigation.

\section{DISCUSSION}

We found MI in all 19 water-based wall paints, BIT in 16 paints, and $\mathrm{MCI}$ in 4 paints, indicating that the first two are the presently preferred preservatives by the paint industry. Furthermore, our results indicate that MI and BIT are often used in combination which should enhance their efficacy and widen the spectrum of antimicrobial effects. We found however no correlations between the concentrations of the two isothiazolinones in the investigated paints (Person correlation coefficient $=-0.126$ ); the concentration ranges of MI and BIT found in the paints were wide and ranged from 10 to $300 \mathrm{ppm}$ for MI and 1.5 to $360 \mathrm{ppm}$ for BIT. MCI is only available in a 3:1 combination with MI e.g. as Kathon CG. In the four cases, where MCI was detected in our study, the concentration of MI was between 4 and 18 times higher than MCI showing that besides $\mathrm{MCI} / \mathrm{MI}$ the manufacturer has also added additional MI. The paint represented a wide range of brands found in Denmark, some of which are international brands as well. Based on this and information from the paint industry about the use of isothiazolinone and particularly MI the tendency seems to be worldwide.

The paints tested in the CLIMPAQ chambers showed the same pattern, namely high concentrations measured almost immediately after painting, followed by decay. Within the first couple of days the concentrations dropped to a constant level and were fluctuating around it for more than a month. The same pattern was observed for MCI found in one of the chambers. Bohn et al. showed a more constant decrease over time compared to our more rapid decrease followed by the prolonged continuous emissions. ${ }^{9}$ The main differences between the two studies is that Bohn et al. sampled all the chamber exhaust air through impingers and applied the paint on glass plates. ${ }^{9}$ In this study there is a constant air exchange in the chamber, and some of the air is collected in the impingers; and finally we have applied the paint to more porous gypsum boards in a somewhat thicker two layer coat. The emission pattern in our study is in agreement with the mathematical models describing VOC emission from the "wet" coating materials. This emission is characterized by two periods: (1) an initial/drying period, where the emission is primarily controlled by the evaporative mass transfer and which is characterized by high emission rate over short time and (2) a later period, controlled by the VOC diffusion within the material, during which the emission rate decreases slowly with time. ${ }^{16,17}$ As presented in Figure 6, showing area-specific emission rates of MI obtained in laboratory and field investigations, the results of 


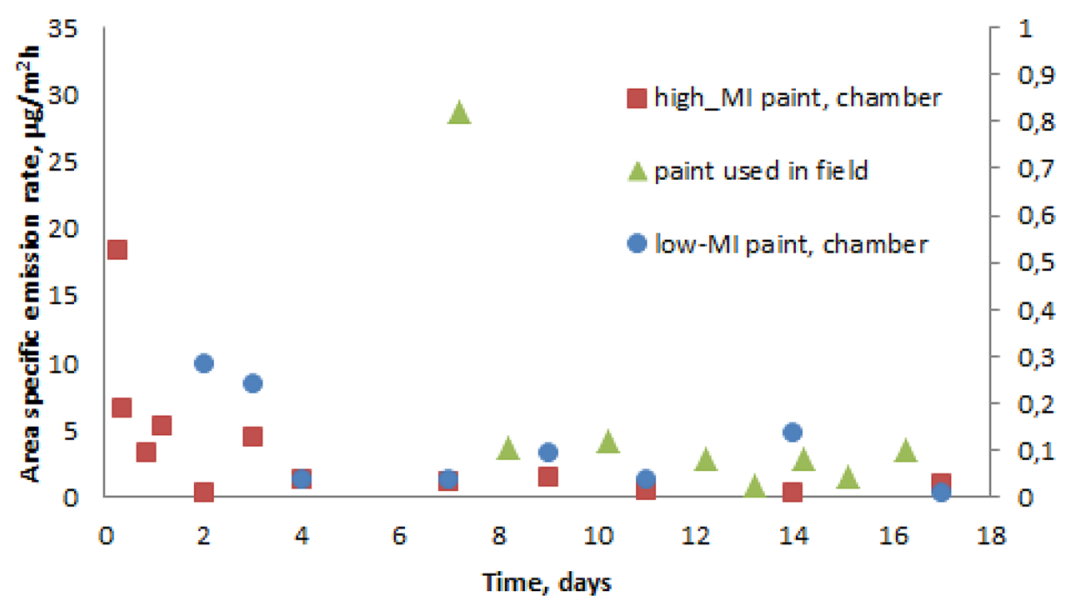

Figure 6. Comparison of area-specific emission rate of MI obtained in laboratory and field investigations. Results of emission from low-MI containing paint should be read on the right scale.

our field experiment are in line with results from the chamber study; however, fluctuation is higher in the second period (Figures 5 and 6) in field experiment compared to laboratory, and the initial period was not caught by our measurements. We were unfortunately unable to set up the experiment during the painting of the apartment, and the paint used in the field was not tested in a laboratory investigation. This would have given the possibility to compare our results from chamber studies to a real life scenario in terms of concentrations that painters are exposed to as well as the concentrations people are exposed to within the first week after application of the paint.

Emission of VOC from wet coating materials is influenced by several factors like coating thickness, VOC concentration in the coating, and substrate parameters but also by environmental factors like air change rate, air velocity, and temperature. ${ }^{16,18-20}$ Most of the existing models simulating VOCs emissions over time are validated based on chamber investigations, ${ }^{17,19}$ where many of these parameters can be controlled. In real life, these parameters are however unstable and difficult to predict, and thus it would be of high value to test the applicability of mathematical models based on data from field investigations.

We used two different paints in one of the chambers, and especially the MI content differed between the two paints (282 ppm MI in no. 17 and $19 \mathrm{ppm}$ in no. 18). This is one of the weaknesses of this study. We expect that if paint no. 17 had been used in both coatings, we would have seen an even greater emission of MI compared to the results shown in Figure 3; however, the emitted concentrations are still several magnitudes higher in Figure 3 compared to Figure 2. Another weakness of this study which needs to be mentioned is the lack of background measurements. As a consequence, especially in the case of the low-MI containing paint, we cannot conclude whether the low long-lasting concentrations we are measuring are in fact background and/or still the emission. We could not find information about the background concentrations in the literature, and neither was the background concentration measured in the two studies found with air measurements. ${ }^{9,21}$ However, we assume that the background air concentrations measured in our indoor climate chambers would be negligible and probably below our detection limits. This assumption is supported by the fact that the chambers are ventilated with filtrated air, with an activated carbon filter installed, which is assumed to remove a significant part of volatile compounds. Furthermore, if the background concentration was significant, it would be possible to detect isothiazolinones already from the beginning of the measurement. As shown in Table 1, we could first detect MI after 4 and $48 \mathrm{~h}$ (in the chamber with high- and low-MI containing paint, respectively). Our results are in line with the two mentioned studies, which also show several weeks lasting emission from MI/MCI containing paints. ${ }^{9,21}$ Finally studies on emissions for "wet" materials show that after a shortlasting initial emission with high emission rates and fast decay, emission of the remaining VOCs in the material is expected to last for a long period of time due to slow diffusion inside the material film and the substrate. The total emission period is expected to last longer when a more porous substrate, like gypsum board, is used. ${ }^{16,17}$

Both the doses as well as repeated exposures are important factors in sensitization and elicitation of allergic contact dermatitis. The emission pattern shows that professional and domestic painters are exposed to a high concentration of emitted MI while painting and in the following hours. Furthermore, the lower but prolonged emission is important for the people living or working in the newly painted rooms. In some of the reported cases of airborne allergic contact dermatitis the patients complained about symptoms several weeks to months after painting. ${ }^{8}$ This could be explained by the documented long lasting emissions at low rates in our measurements.

Currently there is no relevant legislation on the use of MI in industrial products including paints, except that products with more than $0.1 \%(1000 \mathrm{ppm}) \mathrm{MI}$ must be labeled that it "may cause allergic sensitisation" according to rules of selfclassification. This concentration limit is however very high; most products are preserved with concentrations below 1000 ppm (all tested in our study).

Seven of the paints tested in the present study were labeled with the environmental label European Flower, and three of the seven also had the Nordic Swan ecolabel. Both are mainly environmental labels but do however have demands for the use of MI and BIT, which may not be present at concentrations higher than $500 \mathrm{ppm}$, again a limit much higher than what may cause sensitization. Furthermore, ordinary consumers are probably not aware of the exact demands for ecolabels and may believe that the products with the Flower or Swan label are safer to use. Two products with the EU Flower were also labeled with a Swallow from the Swedish Asthma and Allergy Union, and it was stated on the can that these paints contained 
MI, MCI, and BIT. An investigation of the material safety data sheets (MSDS) of the analyzed paints showed that only two of the paints informed about the use of isothiazolinones in the MSDS and that they may cause contact sensitization. It is not illegal for the manufacturer to omit information on isothiazolinone content as long as the concentrations are below the limits set by regulatory authorities. However, as long as the regulatory limits are as high as they are currently, especially for BIT and MI, it is almost impossible for workers and consumers to find out if a given paint is preserved with MI or other isothiazolinones. Moreover it is our experience that the end-users rarely read the MSDS or even know where to find it.

Epidemiological studies on MI contact allergy show that about $1 / 3$ of $\mathrm{MI}$ allergic patients have a relevant exposure to MI through their occupation, and isothiazolinones alone are a frequent cause of occupational contact dermatitis. ${ }^{5,7,11,22}$ Our study shows that both MI and BIT are the most used preservatives in the paint industry. Furthermore, we show that MI emits from newly painted walls and that emissions in low concentrations may last for a long period. Our emission tests and field experiment gives credibility to the clinical observations that allergic contact dermatitis can be caused by emitted and airborne MI from paints. An urgent re-evaluation of the regulatory set limit for especially $\mathrm{MI}$ is needed in order to ensure safe products for painters and consumers.

\section{AUTHOR INFORMATION}

\section{Corresponding Author}

*Phone: +4539777309 Fax: +45 39777118. E-mail: m_d lundov@outlook.dk.

\section{Notes}

The authors declare no competing financial interest.

\section{ACKNOWLEDGMENTS}

The HPLC-MS-MS analyses were performed by Kitty Petersen.

\section{REFERENCES}

(1) Pedersen, N. B. Occupational allergy from 1,2-benzisothiazolin-3one and other preservatives in plastic emulsions. Contact Dermatitis 1976, 2 (6), 340-342.

(2) Lundov, M. D.; Opstrup, M. S.; Johansen, J. D. Methylisothiazolinone contact allergy - a growing epidemic. Contact Dermatitis 2013, 69 (5), 271-275.

(3) Wilkinson, J. D.; Shaw, S.; Andersen, K. E.; Brandao, F. M.; Bruynzeel, D. P.; Bruze, M.; Camarasa, J. M.; Diepgen, T. L.; Ducombs, G.; Frosch, P. J.; Goossens, A.; Lachappelle, J. M.; Lahti, A.; Menné, T.; Seidenari, S.; Tosti, A.; Wahlberg, J. E. Monitoring levels of preservative sensitivity in Europe. A 10-year overview (1991-2000). Contact Dermatitis 2002, 46 (4), 207-210.

(4) Thyssen, J. P.; Engkilde, K.; Lundov, M. D.; Carlsen, B. C.; Menné, T.; Johansen, J. D. Temporal trends of preservative allergy in Denmark (1985-2008). Contact Dermatitis 2010, 62 (2), 102-108.

(5) Geier, J.; Lessmann, H.; Schnuch, A.; Uter, W. Recent increase in allergic reactions to methylchloroisothiazolinone/methylisothiazolinone: is methylisothiazolinone the culprit? Contact Dermatitis 2012, 67 (6), 334-341.

(6) Goncalo, M.; Goossens, A. Whilst Rome burns: the epidemic of contact allergy to methylisothiazolinone. Contact Dermatitis 2013, 68 (5), 257-258.

(7) Mose, A. P.; Lundov, M. D.; Zachariae, C.; Menné, T.; Veien, N. K.; Laurberg, G.; Kaaber, K.; Avnstorp, C.; Andersen, K. E.; Paulsen, E.; Gotthard, M. C.; Sommerlund, M.; Danielsen, A.; Thormann, J.; Kristensen, O.; Kristensen, B.; Andersen, B. L.; Vissing, S.; Nielsen, N. H.; Johansen, J. D. Occupational contact dermatitis in painters - an analysis of patch test data from the Danish Contact Dermatitis Group. Contact Dermatitis 2012, 67 (5), 293-297.

(8) Lundov, M. D.; Mosbech, H.; Thyssen, J. P.; Menné, T.; Zachariae, C. Two cases of airborne contact dermatitis caused by methylisothiazolinone in wall paint. Contact Dermatitis 2011, 65 (3), 176-179.

(9) Bohn, S.; Niederer, M.; Brehm, K.; Bircher, A. J. Airborne contact dermatitis from methylchloroisothiazolinone in wall paint. Abolition of symptoms by chemical allergen inactivation. Contact Dermatitis 2000, 42 (4), 196-201.

(10) Kaae, J.; Menné, T.; Thyssen, J. P. Presumed primary contact sensitization to methylisothiazolinone from paint: a chemical that became airborne. Contact Dermatitis 2012, 66 (6), 341-342.

(11) Lundov, M. D.; Zachariae, C.; Menné, T.; Johansen, J. D. Airborne exposure to preservative methylisothiazolinone causes severe allergic reactions. BMJ [Br. Med. J.] 2012, 345, e8221.

(12) Lundov, M. D.; Friis, U. F.; Menne, T.; Johansen, J. D. Methylisothiazolinone in paint forces a patient out of her apartment. Contact Dermatitis 2013, 69 (4), 252-253.

(13) Bregnbak, D.; Johansen, J. D. Airborne sensitization to isothiazolinones observed in a 3-month-old boy. Contact Dermatitis 2013, 69 (1), 55-56.

(14) Bregnbak, D.; Lundov, M. D.; Zachariae, C.; Menne, T.; Johansen, J. D. Five cases of severe chronic dermatitis caused by isothiazolinones. Contact Dermatitis 2013, 69 (1), 57-59.

(15) Gunnarsen, L.; Nielsen, P. A.; Wolkoff, P. Design and characterization of the CLIMPAQ Chamber for Laboratory Investigations of Materials, Pollution and Air Quality. Indoor Air 1994, 4 (1), 56-62.

(16) Zhang, J. S.; Shaw, C. Y. Modelling of Volatile Organic Compound (VOC) Emissions From Building Materials/Furnishings - A Literature Review; IRC/NRC CMEIAQ: report 3.1.a; 1997.

(17) Yang, X.; Chen, Q.; Zeng, J.; Zhang, J. S.; Shaw, C. Y. A mass transfer model for simulating volatile organic compound emissions from 'wet' coating materials applied to absorptive substrates. Int. J. Heat Mass Transfer 2001, 44 (9), 1803-1815.

(18) Altinkaya, S. A. Predicting emission characteristics of volatile organic compounds from wet surface coatings. Chem. Eng. J 2009, 155 (3), 586-593.

(19) Zang, L. Z.; Niu, J. L. Effect of substrate parameters on the emission of volatile organic compounds from wet coating materials. Build. Environ. 2003, 38 (7), 939-946.

(20) Yang, X.; Chen, Q.; Zeng, J.; Zhang, J. S.; Shaw, C. Y. Effects of environmental and test conditions on VOC emissions from "wet" coating materials. Indoor Air 2001, 11 (4), 270-278.

(21) Reinhard, E.; Waeber, R.; Niederer, M.; Maurer, T.; Maly, P.; Scherer, S. Preservation of products with $\mathrm{MCI} / \mathrm{MI}$ in Switzerland. Contact Dermatitis 2001, 45 (5), 257-264.

(22) Lundov, M. D.; Thyssen, J. P.; Zachariae, C.; Johansen, J. D. Prevalence and cause of methylisothiazolinone contact allergy. Contact Dermatitis 2010, 63 (3), 164-167. 